\title{
REDAÇÃO OU PRODUÇÃO TEXTUAL? PROPOSTAS DE ESCRITA DE ESCOLAS PÚBLICAS DE IRATI, PARANÁ
}

Lorena Reck Portela Rebesco ${ }^{1}$

Loremi Loregian Penkal ${ }^{2}$

\begin{abstract}
Resumo
Esta pesquisa, ancorada em Geraldi (1997), Antunes (2003) e Menegassi (2013), procurou analisar se as propostas de produções textuais trabalhadas em um colégio de Irati, Paraná, estão em consonância com os princípios elencados nas Diretrizes Curriculares do Estado do Paraná, DCEs, (ter o que dizer, razão para dizer, destinatários e adequação ao gênero textual escolhido). Por meio da pesquisa procurou-se obter uma amostragem acerca de como os professores e alunos estão desenvolvendo trabalhos que envolvam a produção escrita na atualidade. A metodologia adotada consistiu na análise de comandos de produção textual de dois livros didáticos adotados pela escola pública analisada e na aplicação de sondagem em duas turmas do $2^{\circ}$. e do $3^{\circ}$. ano, ambas do ensino médio, com um total de 92 alunos investigados. Descobriuse que nem todas as propostas atendem aos preceitos estabelecidos pelas DCEs.
\end{abstract}

Palavras-chave: Produção escrita. Propostas. Livros didáticos. Professores.

\section{ESSAY OR TEXTUAL PRODUCTION? WRITING TOPICS IN PUBLIC SCHOOLS IN THE CITY OF IRATI, PARANÁ}

\begin{abstract}
This research, anchored in Geraldi (1997); Antunes (2003) and Menegassi (2013), aimed to analyze if the suggested writing topics in High Schools in the city of Irati, Paraná are in consonance with the listed principles in the Curricular Guidelines of Paraná State, DCEs, (what to write about, the purpose, the addressees and the suitability of the chosen text genre). Through the research it was aimed to collect a sample of how teachers and students are developing assignments that cover current textual production. The methodology used is the analysis of the writing composition tasks in two different textbooks adopted by public schools observed during the research and also a survey applied to 92 students in two High School classes of the 2nd and 3 rd grades $\left(11^{\text {th }}\right.$ and $\left.12^{\text {th }}\right)$. It turned out that not all proposals meet the rules established by the DCEs.
\end{abstract}

Key words: Writing Production. Writing topics. Textbooks. Teachers.

\section{INTRODUÇÃO}

A produção escrita costuma ser uma das grandes dificuldades dos alunos. No momento

\footnotetext{
${ }^{1}$ Universidade Estadual do Centro-Oeste (Unicentro), Irati - Paraná - Brasil. Graduanda em Letras Português pela Universidade Estadual do Centro Oeste (Unicentro). ORCID < http://orcid.org/0000-0002-4729-8356>. E-mail: lorena_reck@hotmail.com.

${ }^{2}$ Universidade Estadual do Centro-Oeste (Unicentro), Irati - Paraná - Brasil. Doutora em Letras/Linguística pela Universidade Federal do Paraná (UFPR). É professora da graduação em Letras/Fonoaudiologia e do Programa de Pós-Graduação em Letras da Universidade Estadual do Centro-Oeste (Unicentro). ORCID < https://orcid.org/0000-0002-1713-561X>. E-mail: 1lpenkal@irati.unicentro.br.
} 
de produzir um texto escrito, a depender do gênero textual solicitado pelo professor, os alunos apontam, entre outras coisas, que não possuem ideias, que não conseguem transpor para o papel aquilo que fazem tão facilmente na oralidade, que é difícil fazer a introdução, desenvolvimento e conclusão, entre outras questões.

Dessa forma, este trabalho teve a intenção de analisar como se dão as propostas de produções textuais em uma escola de Irati, no Paraná. Para tanto, foi realizada uma pesquisa bibliográfica sobre o tema e, posteriormente, ocorreu a pesquisa de campo, a qual teve duas fontes: análise de livros didáticos e aplicação de sondagem aos alunos.

A leitura deste artigo é indicada para todos aqueles que trabalham com alunos da Educação Básico como, por exemplo, participantes do Programa de Iniciação à Docência (PIBID), estagiários e docentes. Compreendemos que, antes de ser desenvolvido qualquer trabalho sobre a produção textual, é imprescindível saber qual é o estado da arte nas escolas, ou seja, como os professores e alunos estão desenvolvendo essa atividade na prática.

Conforme explicaremos adiante no desenvolvimento do trabalho, a produção escrita já foi ancorada por diversas concepções, de modo que, dependendo do período histórico, ela foi ensinada aos alunos de maneiras diferentes. Em síntese, são conhecidas quatro concepções de escrita: (a) escrita com foco na língua (ênfase na gramática); (b) escrita como dom/inspiração; (c) escrita como consequência (geralmente decorrente de um trabalho extraclasse) e (d) escrita como trabalho (MENEGASSI, 2013).

Essa última concepção é a que se encontra difundida nas Diretrizes Curriculares Estaduais (DCEs) do Estado do Paraná (2008) e está amparada na Teoria Dialógica da Linguagem, defendida por Bakhtin e seguidores. Segundo essa teoria, para produzir um texto o aluno precisa passar por um processo que envolve: planejamento, execução do texto escrito, revisão e reescrita. O aluno deve ter conhecimento sobre: (a) o que vai dizer, ou seja, se informar sobre o tema; (b) saber quem é o destinatário de sua produção (interlocutor); (c) a finalidade do texto; (d) o gênero escolhido e as peculiaridades a ele inerentes, como, por exemplo, organização composicional e estilo de linguagem (MENEGASSI, 2013).

Dessa forma, tanto a análise das propostas dos livros didáticos, quanto o questionário aplicado aos alunos, tentou descobrir se nas escolas analisadas está sendo desenvolvida a escrita como trabalho, pois, de acordo com as DCEs (BRASIL, 1998), essa concepção tornaria a prática da escrita algo mais completo e eficiente, de modo que "o aluno possa enfrentar o mundo atual como cidadão participativo, reflexivo e autônomo, conhecedor de seus direitos e deveres" (BRASIL, 1998, p. 109). 


\section{CONDIÇÕES NECESSÁRIAS PARA A PRODUÇÃO DE UM TEXTO}

De acordo com Geraldi (1997), para se produzir um texto, em qualquer gênero, é necessário que: (a) o autor tenha o que dizer; (b) tenha uma razão para dizer; (c) tenha interlocutores; (d) que o locutor se constitua como tal; e) se escolham estratégias para realizar os itens anteriores ( $a, b, c$ e d). Tais procedimentos, também, são difundidos por outros autores e mesmo pelos documentos oficiais, a exemplo da professora Irandé Antunes e das DCEs. Para melhor explicar cada um destes itens, necessário se faz analisá-los separadamente.

Considerando que a escrita é uma forma de comunicação e é por meio dela que expomos nossos pensamentos, nossa percepção do mundo, nossos sentimentos, nossas crenças, ter o que dizer é um pressuposto básico e lógico para se produzir um bom texto. Por isso, é muito importante pensar, ter ideias, buscar informações e sensações, ampliar nossos horizontes. Consequentemente, as palavras virão e a prática da escrita será aperfeiçoada com o decorrer do tempo (ANTUNES, 2003).

Geraldi (1997) pondera que o sujeito que escreve, ao elaborar um texto, deve ter motivos importantes para tal. Ele não deve escrever apenas para realizar uma tarefa proposta pelo professor, ou simplesmente para preencher linhas em branco. Ainda de acordo com o autor, quando escrevemos, podemos ter a intenção de reivindicar um direito, comparar coisas ou situações, agradar alguém, denunciar um fato, mostrar conhecimento sobre algo, entre outras razões para dizer (GERALDI, 1997). É imprescindível encontrar motivações internas para escrever um texto, pois quando isso ocorre tem-se um trabalho, e não apenas uma tarefa cumprida. Por exemplo, ao propor-se uma produção de texto sobre a própria família, possivelmente surgiria em cada aluno a vontade de descobrir seu passado e compartilhar com seus colegas algumas peculiaridades, semelhanças ou diferenças pertinentes a sua origem (GERALDI, 1997).

Embora o sujeito com o qual o autor interage não esteja presente no momento da produção textual, este destinatário existe e deve ser levado em consideração. É preciso que haja interlocutores, alguém para quem dizer, afinal, a escrita é uma forma de comunicação entre sujeitos. Quem escreve, o faz para alguém, e este alguém é a medida, é o parâmetro que se deve levar em conta no momento em que se decide sobre o que escrever, do quanto se pode dizer e como se pode fazê-lo (ANTUNES, 2003).

Para Antunes (2003), escrever um texto em que o destinatário não existe constitui uma

tarefa dolorosa e inócua, pois falta a referência do outro. É a partir do momento que este faz a leitura do texto que o escritor saberá se atingiu seu objetivo, se conseguir transmitir sua 
mensagem como deveria.Um texto sem destinatário constitui mero treinamento mecânico e aleatório da emissão de sinais, o que na vida cotidiana ninguém faz. Quando nos relacionamos, sempre tentamos dizer algo a alguém. Parece que só a escola não vê isso (ANTUNES, 2003).

Neste sentido, Geraldi (1997) propõe ideias práticas com a finalidade de se buscar um interlocutor no momento da produção dos textos na escola: confecção de livros de histórias, a organização de jornais murais ou jornais escolares, a organização de conferências, exposição e debates de temas, etc. (GERALDI, 1997).

Além disso, o autor, se eventualmente indagado, deve comprovar o que disse no texto, ou seja, deve se comprometer com aquilo que veiculou. As perguntas para que comprove podem não ocorrer, mas sua não ocorrência não isenta o locutor de sua responsabilidade pelas suas falas.

A escolha das estratégias não se dá em abstrato, mas em razão do que se tem a dizer, a razão pela qual se diz e a quem se diz. Por exemplo, as modalidades orais ou escritas pressupõem estratégias diferentes (GERALDI, 1997).

\section{CONCEPÇÕES DE ESCRITA}

O ensino da produção textual brasileira já passou por diversas concepções, utilizadas em diversos períodos históricos. De acordo com Menegassi (2013), são conhecidas quatro concepções de escrita: (a) escrita com foco na língua; (b) escrita como dom/inspiração; (c) escrita como consequência e (d) escrita como trabalho.

A escrita com foco na língua está fundamentada na ideia de que um bom escritor redige seu texto sem erros gramaticais. O professor propõe aos alunos a resolução de diversos exercícios com a finalidade de que eles internalizem as regras gramaticais e escrevam seus textos segundo a norma padrão vigente (MENEGASSI, 2013).

Menegassi (2013) nos ensina que a escrita como dom/inspiração parte do pressuposto de que os alunos devem desenvolver suas produções textuais a partir de uma frase ou comando proposto pelo professor. Não há discussão ou mesmo amparo teórico prévio para o desenvolvimento do texto. Os alunos escrevem com base em seus conhecimentos internalizados a respeito do assunto.

A escrita como consequência é utilizada geralmente quando o professor retira o aluno do perímetro escolar ou foge um pouco das atividades desenvolvidas regularmente. Ocorre quando é transmitido algum vídeo, proposto um passeio para visitar determinado lugar, desenvolvido um debate, entre outras situações. Após a atividade, o professor solicita a confecção de um 
relatório. O problema dessa concepção é que ela traz a ideia de que a produção textual é uma penalidade aplicada em razão da atividade motivadora de interação, dentro ou fora da escola. Além disso, o registro escrito comprova apenas que o aluno participou da atividade, não necessariamente que ele a entendeu (MENEGASSI, 2013).

Já a escrita como trabalho está amparada na Teoria Dialógica da Linguagem, defendida por Bakhtin e nas DCEs do Estado do Paraná. Para produzir um texto o aluno deverá passar por um processo que compreende: planejamento, execução do texto escrito, revisão e reescrita. Assim, a produção textual é um trabalho consciente, planejado, deliberado e repensado. O aluno deve ter conhecimento sobre: a) o que vai dizer; b) saber quem é o destinatário de sua produção (interlocutor); c) a finalidade do texto; d) o gênero escolhido e as peculiaridades a ele inerentes (MENEGASSI, 2013).

De acordo com Menegassi (2013, p. 109), essa concepção de escrita é conhecida como "trabalho" porque dá trabalho, uma vez que o autor precisa preparar, construir, revisar, reescrever e avaliar um texto. Porém, essa concepção torna a prática da escrita algo mais completo e eficiente.

\section{ETAPAS DA PRODUÇÃO ESCRITA}

Feitas essas considerações e explicado por que a concepção dialógica da escrita como trabalho deve ser priorizada no contexto escolar, torna-se importante tecer algumas considerações a respeito das etapas que envolvem a produção textual.

A primeira delas é a etapa do planejamento que requer que o professor e o aluno planejem o que vai ser desenvolvido, pesquisem sobre o assunto, leiam artigos, jornais, revistas, livros. Nesta etapa, verifica-se a esfera social em que o texto circula, delimita-se o tema, define-se o objetivo e a intenção com que se escreverá, pensando em quais serão os possíveis interlocutores, enfim é uma organização das ideias (PARANÁ, 2008). Este é o espaço de pensar como as informações e os argumentos serão distribuídos no texto. É o momento de delinear a planta do edificio que se vai construir (ANTUNES, 2003).

A etapa da escrita é a que se procura escrever a primeira versão sobre o trabalho proposto, observando-se a temática, o gênero e o interlocutor. É a hora de selecionar os argumentos, pensamentos, de modo geral, coloca-se em prática tudo o que foi planejado (PARANÁ, 2008). É neste instante que o escritor irá escolher as palavras apropriadas (léxico), e a partir delas construir peças inteiras que demonstrem suas ideias (sintaxe) em conformidade com o que foi previamente planejado. Também é momento da analisar se o que está sendo escrito possui 
sentido e relevância (ANTUNES, 2003).

Na etapa da revisão e da reescrita, é hora de rever o que foi escrito, refletir sobre os argumentos desenvolvidos, analisar se os objetivos foram atingidos, verificar se o que foi escrito está contemplado na temática proposta, se a linguagem está clara e objetiva, rever as normas de sintaxe (estruturação das frases), ortografia, pontuação e paragrafação (PARANÁ, 2008). Conforme Antunes, "é a hora da revisão (da primeira, talvez), para decidir sobre o que fica, o que sai, o que se reformula. Como afirmou Hemingway: A cesta de papéis é o primeiro móvel da casa de um escritor" (ANTUNES, 2003, p. 55).

\section{RESULTADOS E DISCUSSÃO}

Pontuadas e estabelecidas as questões teóricas sobre as condições necessárias para o desenvolvimento de uma produção textual, passa-se neste momento à apresentação e à análise dos dados gerados na pesquisa de campo, que teve duas fontes: a análise de livros didáticos e a aplicação de sondagem aos alunos.

Foram analisadas as propostas de um texto dissertativo argumentativo e de um artigo de opinião de dois livros didáticos de Língua Portuguesa do terceiro ano do Ensino Médio: Português: Linguagem em conexão de Sette, Travalha e Barros (2013) e Língua Portuguesa: Linguagem e interação de Faraco, Moura e Maruxo Junior (2013).

$\mathrm{Na}$ pesquisa de campo, 92 alunos, de dois colégios públicos de Irati - Paraná, responderam a um questionário de nove perguntas com respostas de múltipla escolha, para investigar se na prática as produções textuais são desenvolvidas em consonância com os parâmetros estabelecidos pelas DCEs do Estado do Paraná. Entre outras coisas, tentou-se descobrir: (a) a quantidade mensal de textos produzidos pelos alunos; (b) se há um preparo para a escrita; (c) quem elabora as propostas (professor ou livro didático); (d) se há a correção e revisão textuais; (e) quem são os destinatários dessas produções; (f) se os alunos admitem ter dificuldades com a produção escrita.

\subsection{LIVROS DIDÁTICOS}

No livro Português: Linguagem em conexão, de Sette, Travalha e Barros, há uma proposta de um artigo de opinião, cujo tema é "Querer ser famoso pode ser um problema?" (SETTE, TRAVALHA, BARROS, 2013, p. 389). Em um primeiro momento os autores definem o que é um artigo de opinião e quais são suas principais características e a seguir, são 
propostas questões de pré-leitura sobre o tema, como por exemplo, se há diferenças entre ser famoso, ter prestígio ou sucesso (SETTE, TRAVALHA, BARROS, 2013, p. 386-391).

$\mathrm{Na}$ sequência, os autores apresentaram quatro artigos de opinião sobre a temática fama, com a intenção de produzir reflexões e desenvolver argumentos para a produção textual. A partir dessas leituras foram propostas questões de nível inferencial e interpretativo (SETTE, TRAVALHA, BARROS, 2013).

Sob essa perspectiva, o livro didático encontra-se em consonância com as DCEs do Estado do Paraná, pois os artigos de opinião apresentados pelos autores se mostraram muito interessantes, constituindo um material importante para que os alunos possam ter o que dizer em suas produções.

Os autores também apresentaram o artigo de opinião destacando quais suas características, finalidades e estrutura e apresentaram o que pode ser feito na introdução, no desenvolvimento e na conclusão. Sette, Travalha e Barros (2013) também propuseram a atividade de correção e reescrita, sugerindo diferentes ideias para que os próprios alunos pudessem corrigir suas produções. Por fim, os autores indicaram quais seriam os destinatários do artigo de opinião produzido: jornal destinado aos jovens, site ou blog da escola ou, ainda, o mural da turma.

Conclui-se, portanto, que a proposta do livro utilizou a escrita como trabalho e, portanto, está amparada na Teoria Dialógica da Linguagem defendida por Bakhtin e pelas DCEs.

Já no livro Língua Portuguesa: Linguagem e interação, de Faraco, Moura e Maruxo Junior (2013), foi sugerida a produção de uma dissertação em prosa. Em um primeiro momento, os autores esclareceram que esse tipo de produção é muito recorrente em vestibulares, concursos e provas do ENEM. Na sequência, transcreveram um modelo de texto dissertativo, cujo título é "Vínculos que superam as diferenças" (FARACO, MOURA, MARUXO JUNIOR, 2014, p. 319).

Foram elaboradas questões de nível interpretativo, metalinguístico (uso de conjunções adversativas) e de localização (identificação de argumentos e tese). Os autores também solicitaram aos alunos a pesquisa de outros modelos de textos argumentativos (FARACO, MOURA, MARUXO JUNIOR, 2014).

Os autores reiteraram as explicações sobre a parte estrutural de uma dissertação (introdução, tese, argumentos e conclusão), salientaram que é para ser evitada a utilização de pronomes em primeira pessoa nesse tipo de texto, explicaram que é necessário ter um cuidado especial com a variedade padrão da língua, com a pontuação, com a estruturação gráfica e a letra (FARACO, MOURA, MARUXO JUNIOR, 2014). 


\section{Linguagens - Revista de Letras, Artes e Comunicação - ISSN 1981- 9943 \\ Blumenau, v. 15, n. 1, p. 167-181, jan./abr. 2021. \\ DOI: http://dx.doi.org/10.7867/1981-9943.2021v15n1p167-181}

Para finalizar, o livro didático sugere a seguinte produção:

Imagine que você vai prestar um exame vestibular com essa proposta para a redação: o candidato deve discorrer sobre suas perspectivas em relação à futura carreira profissional e ao mundo de trabalho.

a) Redija uma dissertação em prosa com base nesse tema.

b) Com base nas características textuais do gênero dissertação em prosa comentadas nesta seção, avalie sua própria produção textual.

c) Discuta com os colegas e o professor os resultados dessa análise e registrem suas conclusões. (FARACO, MOURA, MARUXO JUNIOR, 2014, p. 321).

Verifica-se que a referida proposta não atende aos preceitos estabelecidos pelas DCEs do Estado do Paraná, já que apenas com o material apresentado no livro didático, o aluno não terá, minimamente, o que dizer sobre o tema proposto. Isso porque o texto dado como modelo, "Vínculos que superam as diferenças", fala sobre "relações de amizade", ao passo que o comando da produção requer uma escrita sobre "perspectivas sobre a futura carreira profissional".

Além disso, não foi apresentado qualquer suporte teórico sobre o tema da redação proposta "perspectivas sobre a futura carreira profissional" e nem foram solicitadas pesquisas em artigos, revistas, blogs, etc que pudessem fomentar ideias, desenvolver argumentos e propiciar conclusões. Enfim, ignorou-se uma importante fase, a do planejamento.

Esse tipo de escrita, segundo Menegassi (2013), é aquela fundamentada no dom/inspiração, como se fosse algo "divino", partindo do pressuposto de que os alunos devem desenvolver suas produções textuais a partir de uma frase ou comando proposto pelo professor. Não há discussão ou mesmo amparo teórico prévio para o desenvolvimento do texto e os alunos escrevem com base em seus conhecimentos internalizados a respeito do assunto (MENEGASSI, 2013).

Também foi verificado que a proposta deste livro não possui um destinatário concreto, já que o os autores apenas disseram para o aluno imaginar que o texto seria escrito para um exame de um vestibular. Por fim, a proposta não solicita a reescrita das produções, de modo que: se perde a oportunidade de rever o que foi escrito, de pensar sobre a coerência da tese e dos argumentos, de analisar se os objetivos foram conquistados, de verificar se não houve fuga do tema, de constatar se a linguagem utilizada se mostrou apropriada, de corrigir erros ortográficos, entre outras possibilidades de revisão.

Portanto, conclui-se que a proposta deste livro, em específico, não está em consonância com a Teoria Dialógica da Linguagem defendida por Bakhtin e pelas DCEs.

\subsection{SONDAGEM}


As sondagens foram realizadas em duas escolas públicas da cidade de Irati, no Paraná, ambas parceiras do PIBID, no ano letivo de 2014, em duas salas do $2^{\circ}$. e duas do $3^{\circ}$. ano do ensino médio, com um total de 92 alunos participantes.

A seguir, no gráfico 1, observa-se o percentual das respostas dadas pelos alunos ao questionamento:

Gráfico 1. O que se estuda nas aulas de Português?

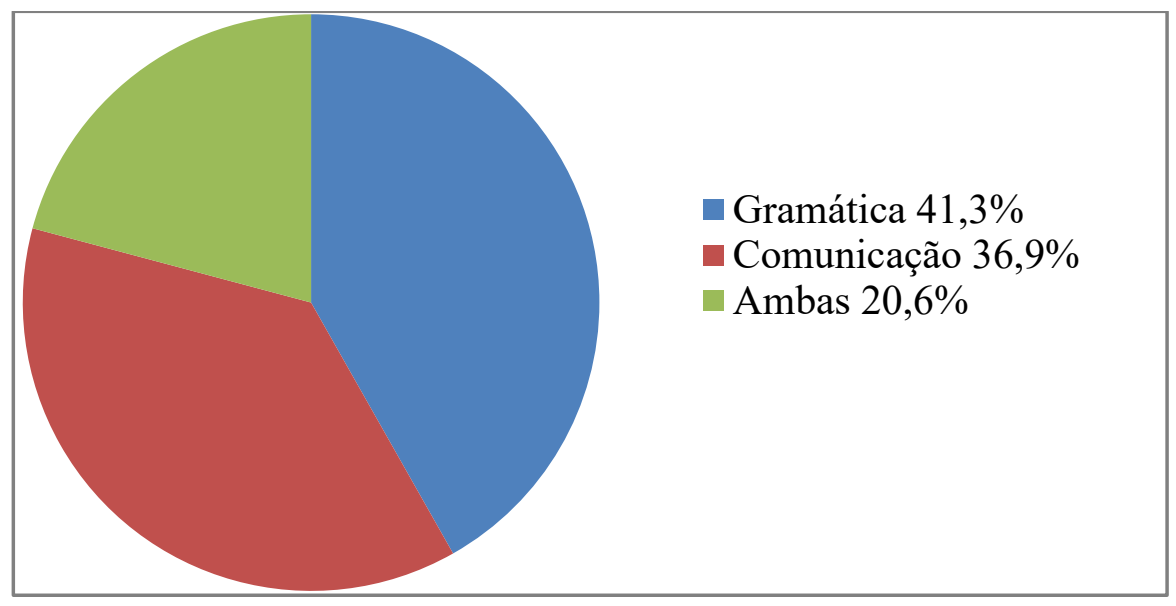

Fonte: elaboração das autoras.

É interessante observar que, gradativamente, os professores estão trabalhando com a Língua Portuguesa com a finalidade de melhorar a comunicação entre as pessoas, ou seja, com o intuito de desenvolver habilidades de expressão e compreensão textual. Isto não significa, no entanto, que o ensino da metalinguagem (gramática) não seja importante, mas sim que este não deveria ser o principal objetivo do ensino da língua.

Gráfico 2. Quantidade de textos produzidos pelos alunos ao mês

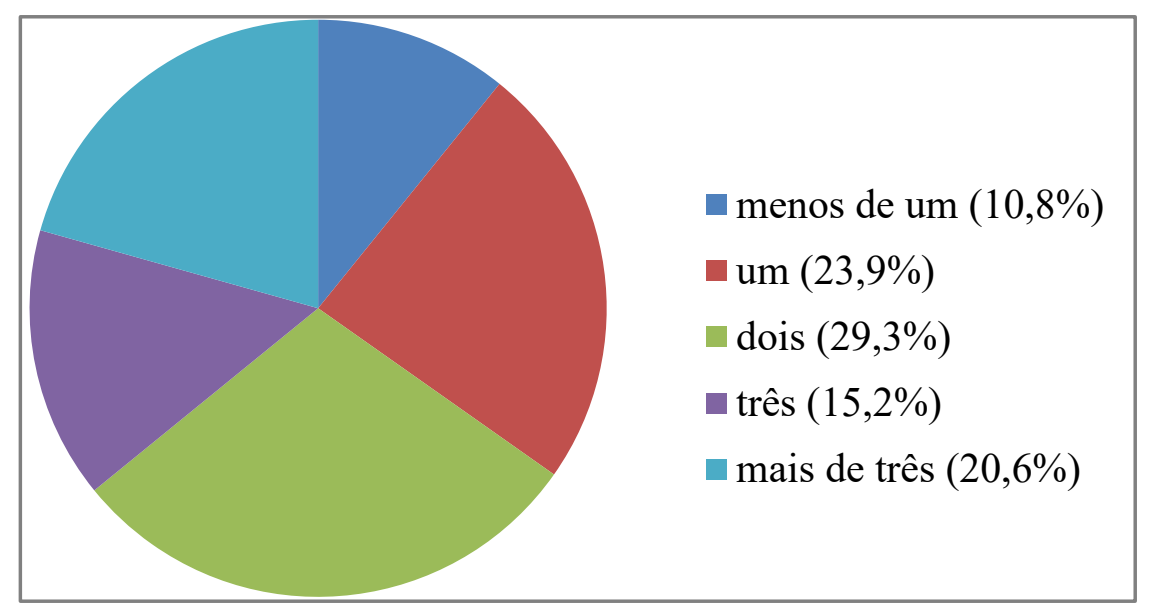


Fonte: elaboração das autoras.

Gráfico 3. Tema das últimas produções

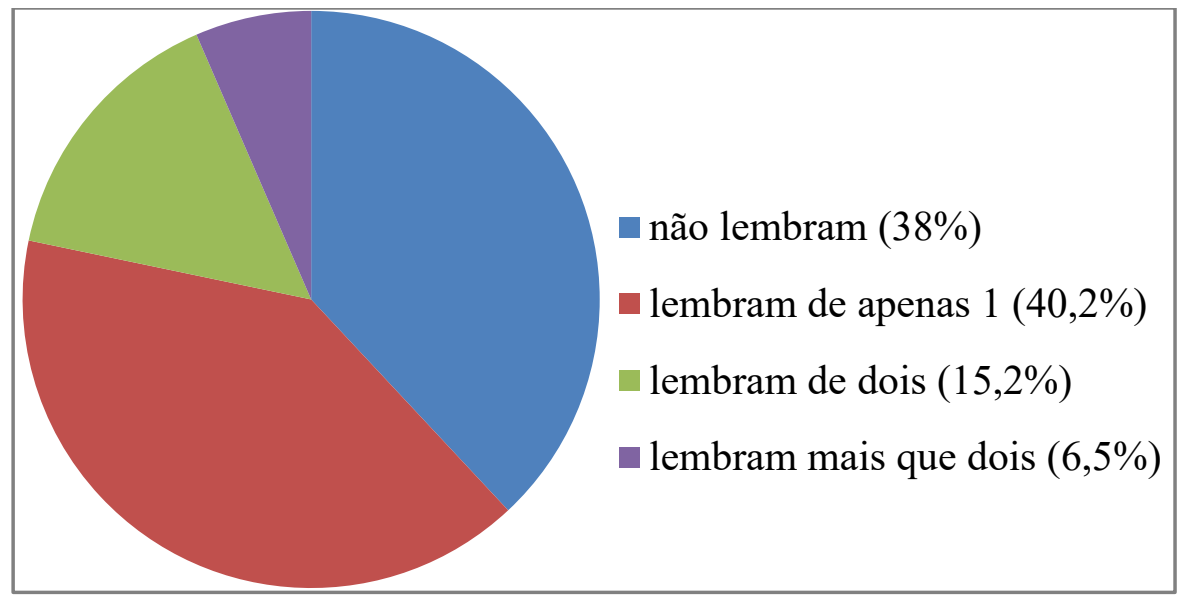

Fonte: elaboração das autoras.

Considerando os gráficos 2 e 3 , é possível perceber que, embora a quantidade de produções mensais seja relativamente alta (uma a três por mês), a maioria dos alunos não consegue lembrar sequer o tema delas (38\% não lembram e 40,2\% lembram de apenas uma).

Diante desses dados, questiona-se: esses alunos tiveram uma razão para escrever? Tiveram um motivo importante para tal? Ou apenas preencheram linhas em branco a fim de cumprir a tarefa solicitada pelo professor? Conforme apontamos, para Geraldi (1997), é imprescindível encontrar motivações internas para escrever um texto, pois quando isso ocorre tem-se um trabalho e não apenas uma tarefa cumprida.

Gráfico 4. Ocorrência de planejamento antes da escrita

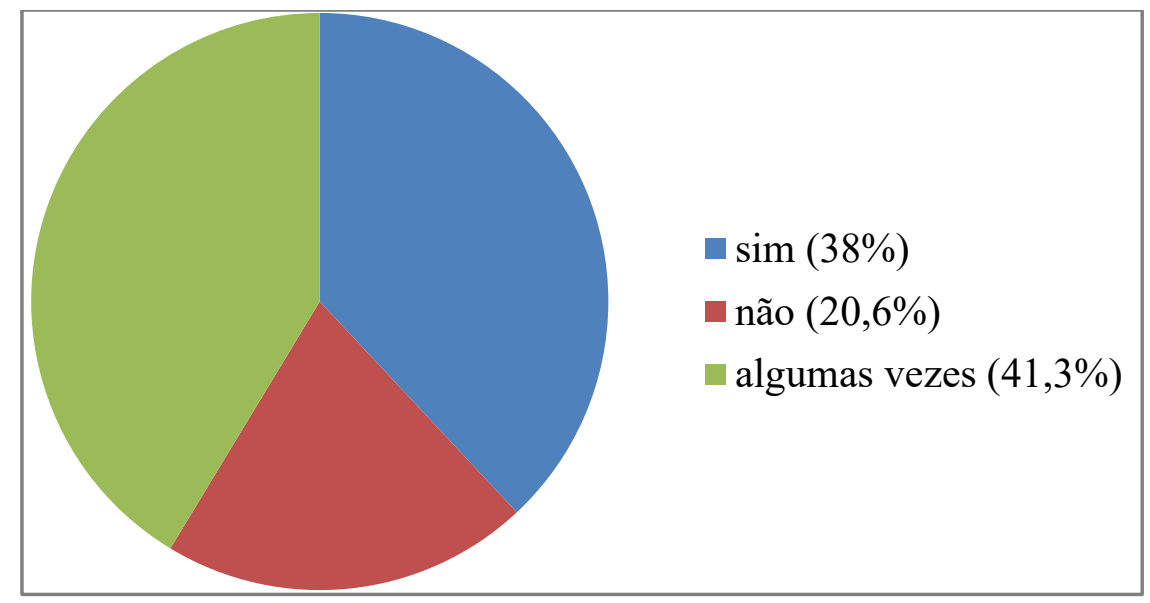

Fonte: elaboração das autoras. 
Por meio do gráfico 4, verifica-se que nem sempre o professor realiza a etapa de planejamento das produções escritas com os alunos (41,3\%), se somarmos a esse montante os outros $20,6 \%$ dos alunos que disseram que não há esse preparo, teremos um resultado de $61,9 \%$, ou seja, em mais da metade dos casos a fase do planejamento não ocorre ou ocorre apenas algumas vezes. Conforme já discutimos anteriormente, essa etapa deveria ocorrer sempre, pois é condição imprescindível para que o aluno tenha o que dizer, já que ter um amparo teórico sobre o assunto a ser discutido é um pressuposto lógico para se produzir um bom texto.

Gráfico 5. Quem elabora as propostas?

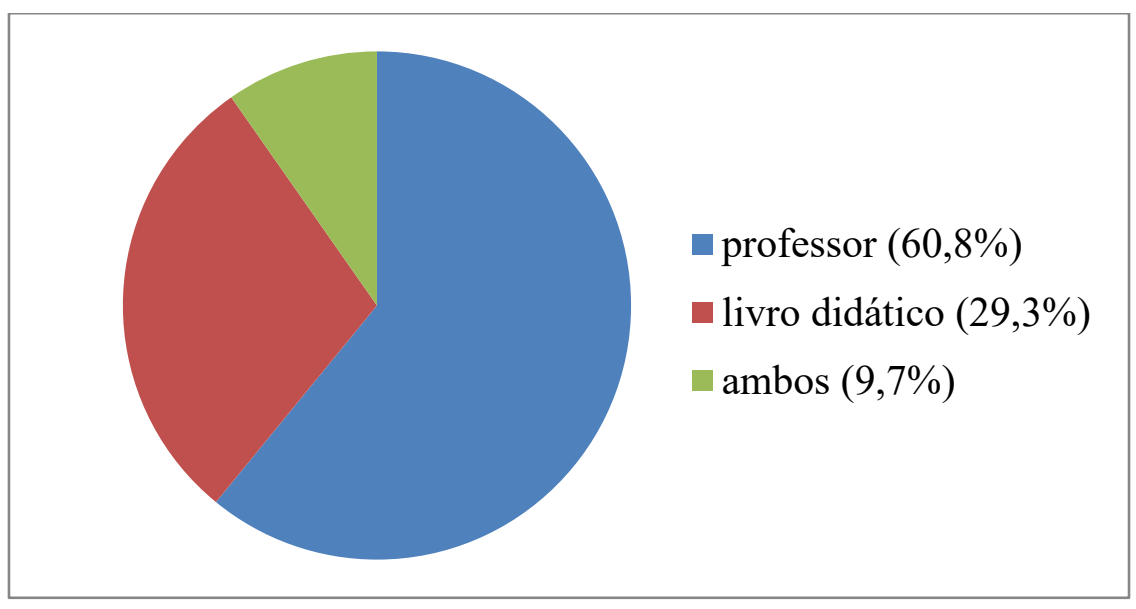

Fonte: elaboração das autoras.

Gráfico 6. Quem são os destinatários das produções?

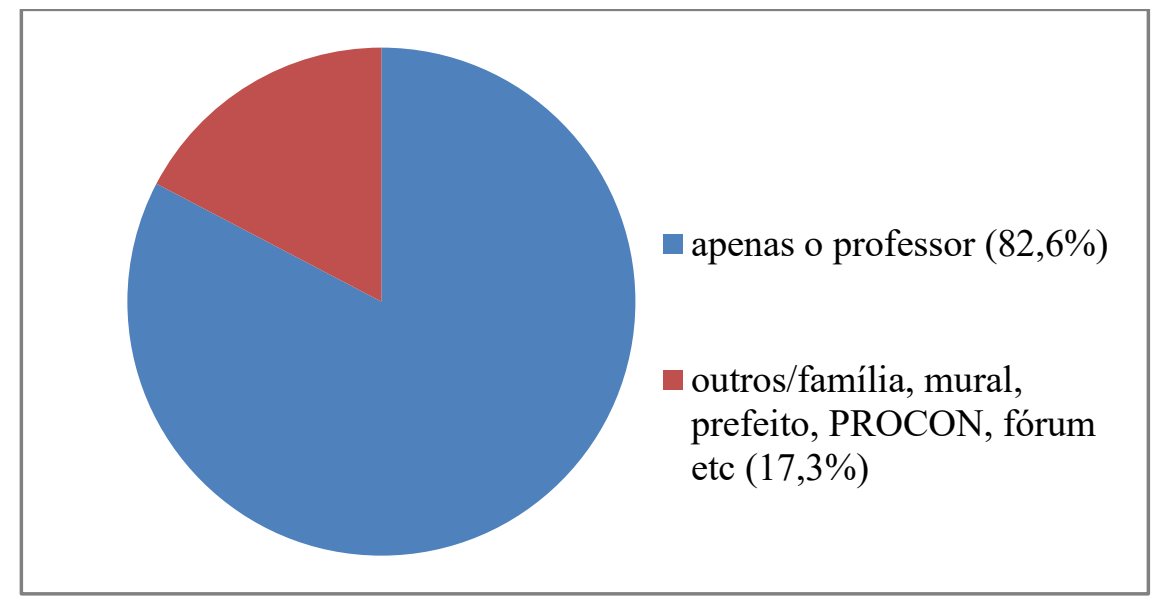

Fonte: elaboração das autoras.

De acordo com os dados apresentados nos gráficos 5 e 6 , constatamos que $82,6 \%$ das produções textuais têm como único destinatário o professor. Seria interessante diversificar esse interlocutor, com a escrita de textos para blogs, mural da escola, jornais, alunos de outras 
escolas, família, prefeito, PROCON, Fórum. Isso porque, mesmo que os destinatários dos textos não estejam presentes no momento da produção textual, eles devem existir e também devem ser levados em consideração, pois a escrita é uma forma de interação entre as pessoas.

Gráfico 7. Desenvolvimento do trabalho de correção

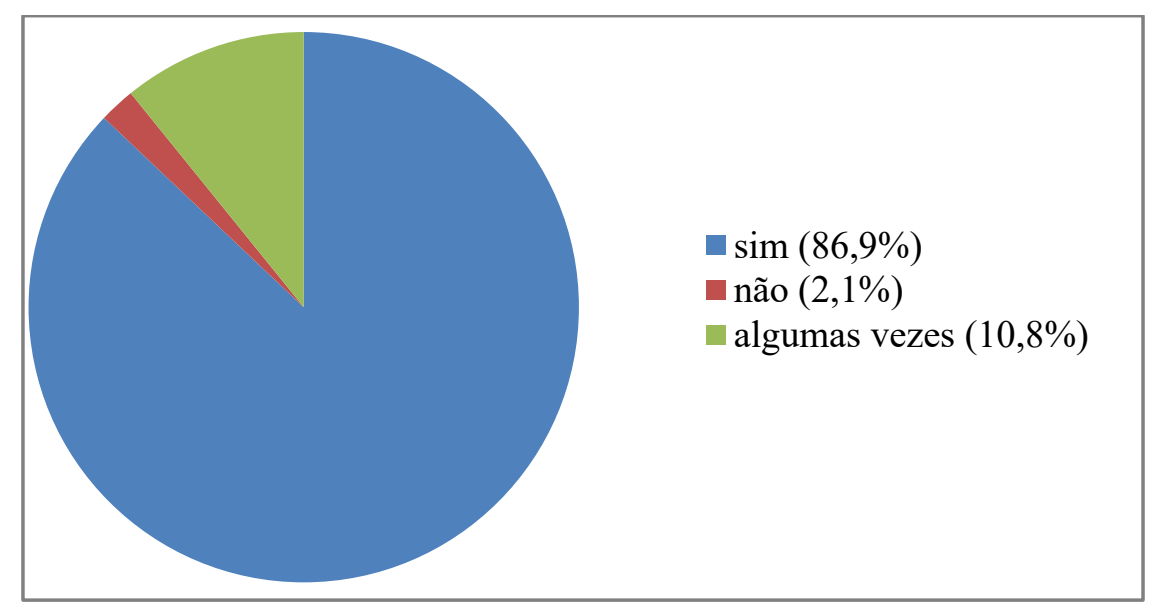

Fonte: elaboração das autoras.

Gráfico 8. Desenvolvimento do trabalho de reescrita

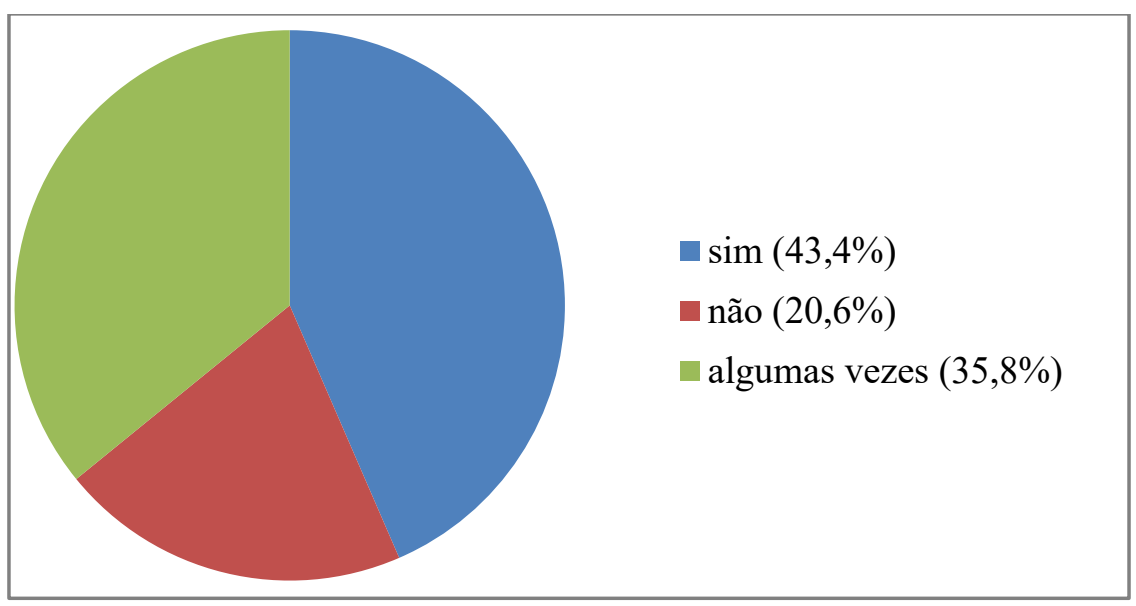

Fonte: elaboração das autoras.

Verifica-se que em $86,9 \%$ dos casos o professor faz a correção das produções textuais e dá retorno aos alunos, contudo, isso não é o suficiente, pois o gráfico 8 mostra que nem sempre a reescrita acontece. Se somarmos a porcentagem de alunos que disseram que a reescrita não ocorre ou ocorre algumas vezes, teremos um total de $56,4 \%$.

De acordo com as DCEs do Estado do Paraná, a reescrita deve ocorrer sempre, pois é nela que o estudante tem a chance de rever o que foi escrito, refletir sobre os argumentos desenvolvidos, analisar se os objetivos foram conquistados, se houve respeito à temática 
abordada, se a linguagem está clara e objetiva, rever as normas de sintaxe (estruturação das frases), ortografia, pontuação e paragrafação (PARANÁ, 2008). Ou seja, os dados evidenciam a importância de o professor, além de apontar as questões a serem revistas nos textos dos alunos, dar um feedback efetivo a eles. Sem este retorno, não há uma proposição efetiva para que a reescrita ocorra de fato.

Gráfico 9. Alunos que admitem ter dificuldades com a produção escrita

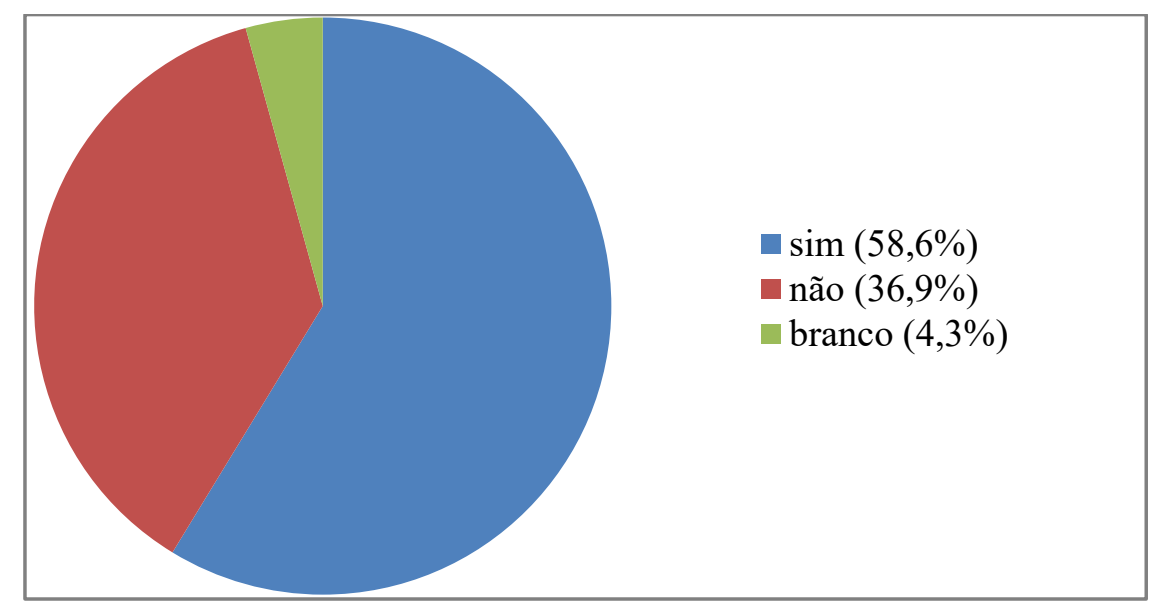

Fonte: elaboração das autoras.

O gráfico 9 mostra a constatação de que os próprios alunos admitem ter dificuldades com a produção escrita $(58,6 \%)$, de modo que é importante que os professores façam um levantamento efetivo dessas dificuldades dos alunos e que busquem, modo efetivo, maneiras de supri-las. Além disso, é importante o desenvolvimento de um trabalho conjunto, entre professores e elaboradores de livros didáticos, a fim de que haja o aprimoramento constante das atividades propostas e que ocorra o aperfeiçoamento efetivo da escrita dos alunos.

\section{CONSIDERAÇÕES FINAIS}

A pesquisa relatada neste artigo nos permitiu verificar como estão sendo desenvolvidas, as produções textuais em algumas escolas de Irati - Paraná. Os resultados confirmam o previsto e descrito nos livros de Antunes (2003) e Geraldi (1997), de que existem professores e livros didáticos que ainda utilizam metodologias que não demonstram bons resultados em auxiliar os estudantes na escrita dos textos como por exemplo: (a) falta de planejamento (discussão e amparo teórico) antes da escrita; (b) temas que não trazem motivação/razão para os alunos; (c) professores como únicos destinatários das produções; (d) falta de revisão textual; (e) concepção da escrita como dom/inspiração. 
Quem sai perdendo com essa situação é o nosso país, pois quem não consegue "ler o mundo" e estabelecer uma conexão linguística com ele, não tem condições de refletir e participar efetivamente das construções sociais mais importantes.

A mudança desse quadro pode partir também dos professores, seja no momento de elaborar propostas de produções textuais, seja no momento da escolha do livro didático. Se o modelo utilizado não tem se mostrado eficaz, tendo em vista que, conforme apontado na pesquisa aqui apresentada, há dificuldades dos alunos com a interpretação e produção de textos, questiona-se: por que não estudar e desenvolver as novas propostas difundidas pelas Diretrizes Curriculares, bem como por outros documentos norteadores do ensino?

É importante que o aluno, antes de produzir um texto, tenha acesso aos processos de planejamento, execução, revisão e reescrita. Ele precisa saber: (a) o que vai dizer; (b) saber quem é o destinatário de sua produção (interlocutor); (c) a finalidade do texto; (d) o gênero escolhido e as peculiaridades a ele inerentes.

Dessa forma, os alunos terão mais condições de desenvolver um trabalho completo e eficiente, que vá muito além da vida escolar. Ou seja, poderão constituir-se não apenas como bons discentes, mas, principalmente, terão condições efetivas de se tornarem cidadãos reflexivos, críticos, participativos e atuantes. Enfim, poderão se tornar sujeitos de seu próprio dizer.

\section{REFERÊNCIAS}

ANTUNES, I. Aula de Português: encontro e interação. São Paulo: Parábola Editorial, 2003.

BRASIL. MEC. Introdução aos parâmetros curriculares nacionais/Secretaria de Educação Fundamental. Brasília: MEC/SEF, 1997.

BRASIL. MEC. Parâmetros curriculares nacionais de língua portuguesa. Terceiro e quarto ciclos do Ensino Fundamental. Brasília: MEC/SEF, 1998.

COSTA VAL, M. da G. Redação e textualidade. $2^{\text {a }}$ ed. São Paulo: Martins Fontes, 1999.

FARACO, C. E.; MOURA, F.M.; MARUXO JUNIOR, J.H.. Língua Portuguesa:

Linguagem e interação, volume 3. São Paulo: Ed. Ática, 2013.

PARANÁ, Secretaria do Estado da Educação. Superintendência de Educação. Departamento de Ensino Fundamental. Diretrizes Curriculares do Estado do Paraná. Curitiba, 2008.

MENEGASSI, R. J. A revisão de textos na formação docente inicial. In: GONÇALVES, A. V. (orgs.). Interação, gêneros e letramento: a (re)escrita em foco. Campinas, SP: Pontes Editores, 2013. 
GERALDI, J. W. Portos de passagem. 4ª ed. São Paulo: Martins Fontes, 1997.

SETTE, M.G.L.; TRAVALHA, M.A.; BARROS, M.R.S. Português: Linguagem em conexão, volume 3. São Paulo: Ed. Leya, 2013.

Submetido: 22/04/2016 Aceito: $19 / 03 / 2020$ 